\title{
Desde la transdisciplinariedad hacia el auto-conocimiento y el diálogo comunitario de saberes: simplicidad ante la crisis
}

\author{
Enrique Vargas-Madrazo \\ Universidad Veracruzana, Veracruz, México. \\ Email: evargas@uv.mx
}

\begin{abstract}
Resumen: Partiendo de mi experiencia de vida, enmarcada en la crisis, no sólo de la modernidad, sino de la contradicción entre el alma latinoamericana y la imposición desde la globalización de una mecánica social eficientista, abordo cómo se construyen las costumbres del pensamiento en los intelectuales y académicos latinoamericanos. En este contexto reflexiono sobre la crisis civilizatoria-planetaria, identificando al positivismo-racionalismo como una de sus piedras nodales. La transdisciplinariedad y el pensamiento complejo, son abordados como una respuesta valiosa y fértil a la crisis del sistema académico-moderno del conocimiento, proponiendo al mismo tiempo, la necesidad de no detenerse en estos sistemas del pensar como tablas de salvación de la modernidad. Con base en esto, me pregunto si estamos siendo incapaces de percatarnos de las dimensiones de la inviabilidad de una racionalidad que ignora la naturaleza orgánica-holística de nuestro pensamiento. Evidencio también nuestra incapacidad de emprender afectiva y efectivamente formas participativas del conocimiento, así como del diálogo de saberes, proponiendo algunos de los elementos clave para la reconstrucción hacia una praxis académica sustentable.
\end{abstract}

Palabras clave: interculturalidad, intersubjetividad, conocimiento participativo, ética del conocimiento.

\section{From transdisciplinarity towards self-knowledge and community dialogue of knowledges: simplicity at the crisis}

\footnotetext{
Abstract: From my life experience, contextualized by the crisis, not only of modernity, but of the contradiction between the Latin American soul and the imposition from globalization of a social mechanic efficiency, I aboard how customs in intellectual thought are created by Latin American scholars. In this context I analyze on civilizing-planetary crisis, identifying positivism-rationalism as one of its nodal stones. Transdisciplinarity and complex thought are addressed as a valuable and fertile response to the crisis of the modern-academic knowledge system, proposing at the same time, the need to not dwell on these systems of thought as a life guard of modernity. Based on this, I ask myself if we are still unable to realize the dimensions of the inviability of a rationality that ignores the organic-holistic nature of our thinking. I also make evident our inability to effectively and affectively engage in participatory forms of knowledge, as well as on a dialogue on knowledges, and propose some key principles to re-build a sustainable academic practice.

Keywords: interculturality, intersubjectivity, participatory knowledge, ethics of knowledge.
} 


\section{Desde a transdisciplinaridade para o auto-conhecimento e o diálogo comunitário de saberes: simplicidade perante a crise}

Resumo: Com base na minha experiência de vida, emoldurada na crise, não só a modernidade, mas a contradição entre a alma latino-americana e a imposição desde a globalização de uma mecânica social eficientista, abordo como são construídos os hábitos de pensamento em intelectuais e acadêmicos latino-americanos. Neste contexto, reflexiono sobre a crise civilização planetária, identificando ao racionalismopositivismo como uma das suas pedras nodais. A transdisciplinaridade e o pensamento complexo são abordados como uma resposta valiosa e profícua para a crise do sistema de conhecimento acadêmico moderno, propondo ao mesmo tempo, a necessidade de não deter-se sobre estes sistemas de pensamento como tabelas salvação da modernidade. Com base nisso, eu me pergunto se estamos sendo incapazes de perceber as dimensões da impossibilidade de uma racionalidade que ignora a natureza orgânico-holística do nosso pensamento. Evidencio também a nossa incapacidade para realizar efetivamente as formas afetivas e participativas de conhecimento, bem como o diálogo de saberes, oferecendo alguns dos principais elementos para a reconstrução de uma praxis académica sustentável.

Palavras-chave: multiculturalismo, intersubjetividade, conhecimento participativo, ética do conhecimento.

Estamos comprometidos con la humanidad planetaria y en la obra esencial de la vida que consiste en resistir a la muerte. ...solidarizarnos en

la Tierra. ...transformar la especie humana en verdadera humanidad se vuelve el objetivo fundamental y global de toda educación. ...la conciencia de nuestra humanidad en esta era planetaria nos debería conducir a una solidaridad y a una conmiseración recíproca del uno para el otro, de todos

para todos.

Edgar Morin

Conócete a ti mismo...

Mandato socrático

\section{El bucle creativo: la muerte-vida-muerte ${ }^{1}$ fértil}

En la lógica de la academia instaurada como tradición desde el renacimiento tardío y la ilustración, pero sobre todo en el seno de la revolución industrial de los siglos XVIII y XIX, la empresa del conocimiento era como una gran Torre de Babel que crecía y crecía ensanchando su lógica de forma exitosa por todos los confines del mundo. Este estado de cosas se fue consolidando por el planeta en el siglo XX, penetrando en los "países periféricos”, como México, sobre todo hacia la segunda mitad de siglo. Siempre inmersa en crisis pequeñas y mayores, la lógica de la modernidad 
se iba imponiendo no solamente dentro (y a través) de las universidades, en la industria y en el campo, sino en la vida cotidiana de los seres humanos de casi todos los países en el mundo de la posguerra. Sin embargo, en muchos sentidos, la crisis de inviabilidad de la modernidad enraizada desordenadamente sobre los escombros del feudalismo, del colonialismo y del imperialismo capitalista, se hacía sentir ya en diversos ámbitos de las sociedades tanto "desarrolladas" como "tercermundistas" a lo largo de la primera mitad del siglo XX. Quizás la década de los 60’s epitomiza muchos de estos focos de inviabilidad, múltiples ámbitos de crisis que ya explotaban dentro de las sociedades encaminadas en la modernidad. Así me toca nacer (año 1964), en el vórtice de un mundo que muere: el de las ideologías, la familia, la pareja, la educación, los ríos cristalinos, el aire puro, las certezas del bienestar material y monetario, el patriarcalismo, el catolicismo; esto es nacer en la contradicción, nacer en el reconocimiento del homo demens (Morin y Kern 1999) desatendido y negado.

Mi mundo creció en un jsálvese quien pueda! emocional del desmembramiento de la célula familiar tradicional mexicana. Pero además, cruzado por las luchas populares por la justicia social que fue aplastada bajo la bota militar y policial, pretendiendo que todo transcurriera románticamente en unas Olimpiadas "idílicas", en realidad manchadas por la sangre y el silencio.

Esta desesperanza social y humana había quedado plasmada en los corazones de las y los mexicanos y muchos otros países latinoamericanos atrapados por la lógica imperial aterrizada en la "solución” militar para el profundo malestar social acumulado durante décadas y siglos de opresión.

La gran paradoja de nuestro tiempo "moderno" en los "países periféricos” al desarrollo económico-industrial, ha sido la convivencia íntima de este empuje modernizante y eficientista del "México enfilado hacia la globalización capitalista” con el México profundo, repleto de nuestro ser ancestral, anárquico, profundamente mágico-religioso y jocoso. Esta paradoja ha implicado que en este desaforado camino, donde hemos sido literalmente empujados hacia la quimera del desarrollo, tiene lugar la más dolorosa y profunda resistencia, no sólo indígena y zapatista, sino de la gran mayoría de las y los mexicanos que aún vivimos en el seno de la cultura de la tortilla y el chile (sin embargo, para que no lo olvidemos y para hacer aún más incisiva la paradoja, en todos nosotros también está la otra parte, la moderna y eficientista). Esta resistencia expresa el calado de las raíces del México Profundo (Bonfil 1990), de un hacer y un ser mexicano(a) y latinoamericano(a) viviendo esquizofrénicamente en otra espacio-temporalidad, en otra relación con la necesidad muy alejada de la premura por el éxito. Esto nos ha llevado a una especie de bipolaridad neurótica donde tratamos de cumplir con los horarios del empleo, con las cada vez mayores exigencias de la razón instrumental, viviendo al mismo tiempo en un caos creativo y emocional, en una espontaneidad llena de huecos en el tiempo desde nuestra animalidad, en el romanticismo, las fiestas patronales, el cultivo del tiempo perdido de la reunión y de los abrazos llenos de irracionali- 
dad. Esta especie de bipolaridad nos permea por todas partes, reconozcámosla o no, nos marca y nos ayuda a hacer evidente la posibilidad del reconocimiento de la inviabilidad del modelo aparentemente "exitoso" del desarrollo tecnocientífico.

En muchos sentidos, en lo emocional y también en lo racional, los humanos intelectuales hijas e hijos de este mundo en crisis de muerte-vidamuerte, encontramos un cierto espacio de supervivencia a través de una especie de autismo racionalista, en la búsqueda de modelos mentales explicativos que guiarán nuestro actuar en un mundo enfrascado en lograr un sinsentido del desarrollo y la globalización basado en la destrucción tanto del alma humana, como del alma del mundo. Puedo caracterizar esta forma de estar en el seno de la crisis humana del siglo XX, como un intento de rescate de lo esencial en las entrañas del monstruo científico-racional (civilizatorio), en el intento vano de huir del horror del mundo cayéndose a pedazos.

En el vórtex bidireccional hacia el orden racional, por un lado, y de la intuición, la libertad creativa y transgresora, por el otro, se hace presente la pasión, la necesidad de contacto con el otro, de la búsqueda de una conexión con el mundo real creciendo desde la experiencia. En ese espacio, surge una búsqueda de la humanización del conocer-que-es-mi-vivir ${ }^{2}$, nutriendo mi andar por la academia, la cual es ahora parte de mi existencia.

Percibo por mi propia experiencia y por mis conversaciones experienciadas con muchas personas a lo largo de mi vida, que la gran mayoría de los seres humanos y académicos de esta época, compartimos de alguna u otra manera este patrón de crisis en vida-muerte-vida que he descrito brevemente con anterioridad. Consecuentemente, también a mi entender, los procesos mentales-emocionales, y en particular aquellos de la actividad intelectual profesional, están profundamente permeados por las problemáticas y conflictos que crecen en esta encrucijada de la humanidad post-moderna ${ }^{3}$ actual. Tal como argumentaré en las siguientes apartados, el profundizar y atender estos procesos y problemáticas humanas, resulta esencial para generar una transformación de la praxis académica en latinoamérica y en el mundo que sea capaz de responder de forma creativa a los enormes retos socioambientales que tenemos como humanidad en estos momentos históricos (de Sousa Santos 2014).

Dos estructuras sociales coercitivas están en la base de este malestar e inviabilidad que creo nos sacuden a todas y todos en estos tiempos difíciles y excitantes de la humanidad: el androcentrismo-patriarcalismo y la globalización del capitalismo occidental. A mi entender, dos libros expresan de forma sensible y profunda esta moderna humana condición: "Mi nombre es Chellis y me encuentro en recuperación de la civilización occidental" (Glenddening 1994) y, "Mujer y naturaleza: el clamor dentro de ella” (Griffin 1978). Estas hermosas mujeres y seres humanos, no sólo exploran con aguda inspiración las profundas heridas que el patriarcalismo y el androcentrismo han dejado en la psique humana, sino el igualmente doloroso ultraje a nuestra Madre Tierra. De manera que nuestra atención y cuida- 
do a esta fragmentación, no solamente debe ir hacia adentro de nuestro corazón, sino siempre de regreso hacia nuestra comunidad y hacia esta tierra que nos da sustento y sentido existencial, nuestra Pacha Mama. Nuevamente, enfatizo aquí (ver en las siguientes secciones) que en los procesos educativos y en la praxis académica, estos aspectos centrales de la problemática del ser humano actual, deben ser atendidos en cada instante del vivir y el hacer, si es que de forma honesta queremos hacernos cargo de nuestra responsabilidad de construir alternativas sustentables a esta crisis planetaria, humana y educativa en la que nos encontramos como humanidad.

Este pathos, que es camino de ida y vuelta, de callejones sin salida existenciales y de vida, nos expresa de forma evidente, la necesidad de atender de manera sutil y cuidadosa caminos de necesaria sanación. En un artículo previo (Vargas-Madrazo y Rehaag 2012) hemos llamado a este proceso el "re-aprendizaje transdisciplinario para la sanación personal y colectiva”. Con esto entiendo que los seres humanos en nuestro proceso de educación formal y para la vida, nos adentramos en la necesidad de reaprender, de abrir y cerrar nuestro corazón lleno de inteligencia y perceptividad, de mirar en el pasado y el presente de nuestras identificaciones e indoctrinaciones, en busca del renacimiento de la experiencia viva, de la atención delicada y sensitiva tanto a nivel personal, como colectivo. Es por esto que proponemos (Vargas-Madrazo y Rehaag 2012) este caminar de constante re-aprendizaje junto a la Madre Tierra en un constante proceso de sanación, tanto personal como colectiva.

Específicamente dentro de los procesos académicos e intelectuales, llamamos a este constante proceso de auto-eco-sanación ${ }^{4}$ la "vigilia epistemológica”. Es decir, el constante cuidado y atención, respecto a los fundamentos corporales, intelectuales y emocionales en los que estoy forjando mi pensar, conocer y hacer en el mundo.

A mi entender el constante trabajo de vigilia epistemológica implica adentrarse en un compromiso hacia la re-proporcionalización (Illich 1985) tanto de nuestro vivir (nuestro consumo, nuestra huella ecológica, etcétera), como de nuestro pensar e indagar académico del mundo. Identifico a esta actitud ética en el vivir como un llamado profundamente humanista hacia la simplicidad. En las siguientes secciones abordo las implicaciones epistemológicas y del quehacer académico de lo hasta aquí planteado y que nos lleva desde el encerramiento disciplinario y racionalista transitando (literalmente) por la ventana de la transdisciplinariedad y el pensamiento complejo hacia el auto-conocimiento y el diálogo comunitario de saberes.

\section{El camino de la actitud transdisciplinaria: apertura desde un andar constante como ruta de vida}

¿Percibimos quizás que el conocimiento disciplinario tiende a acotarse reiterativamente sobre los bordos de sus objetos y métodos de 
estudio, sobre los alcances de su perspectiva específica de intereses y escuelas de pensamiento?

En este escenario Basarab Nicolescu (Nicolescu 2002) nos recuerda que la necesidad de coherencia y orden interno del hacer disciplinario, se expresa en la auto-exigencia imperativa de aplicación de la lógica aristotélica; sin embargo quizás muchos hemos sentido que este esquema "hace agua" constantemente, al encontrarse con las contradicciones y errores que son parte esencial de la realidad y la complejidad, la cual vive en cada rincón del mundo real (Morin y Kern 1999). Tanto Basarab Nicolescu como Edgar Morin, enfatizan que estas dificultades se derivan, de forma esencial, de la falta de atención e interés a la vigilia o auto-conocimiento de lo que estamos siendo como sujetos del conocer, de ir más allá de la reactividad de nuestras identificaciones con patrones de ideas y/o estructuras emocionales-corporales que controlan, de forma no-consciente, mi ser.

Partiendo de aquí, Basarab Nicolescu nos propone que, de forma complementaria, surge a partir del siglo XX y en particular en el marco de la mecánica cuántica, la necesidad de reconocer que el mundo no opera en un único nivel (continuo) de realidad. Así desde el punto de vista de la física, inescapablemente tenemos que reconocer que existen al menos tres niveles de realidad: los mundos y la experiencia de realidad que se deriva del microscópico-cuántico, del mesoscópico-clásico y del macroscópico-relativista. Basarab Nicolescu afirma que al interior de cada uno de estos niveles de realidad, tienen lugar leyes y fenómenos que albergan eventos homogéneos donde efectivamente podemos observar y esperar "coherencia” lógica.

Dentro de la Metodología Transdisciplinaria ${ }^{5}$, Basarab Nicolescu aborda de frente algunas de las raíces fundamentales de la actual problemática civilizatoria que como humanidad tenemos en torno al conocimiento. En particular dentro del nivel de lo lógico, atiende la problemática del tercero excluido: no puede haber un tercer término T, que sea igual a $\mathrm{A}$ y no-A al mismo tiempo. Al aplicar su noción de niveles de realidad a la lógica del tercero incluido de Lupasco, explica que el término T sí puede existir siendo igual a A y no-A, tan sólo hay que tomar consciencia de que T existe en otro nivel de realidad y está ligado lógicamente a A y no-A. Esto es ya mucho para la ciencia convencional, por lo que las y los académicas/os de la lógica establecida, repudian este comportamiento "poco serio" de Basarab Nicolescu. Esta propuesta implica una invitación e impulso movilizador a la apertura para reconocer, explorar y vincular distintos niveles de realidad en nuestro estar y conocer el mundo. Siguiendo la propuesta de Basarab Nicolescu, y paralelamente a lo que Edgar Morin nos plantea, por ejemplo en su hermoso libro Mis demonios (Morin 1995), esta exploración, sólo puede ocurrir desde el auto-conocimiento delicado y corporal de mis niveles de percepción (Nicolescu 2002), o de reconocer desde la experiencia mi estar presente en el complexus ${ }^{6}$ del conocer (Morin 1999). A mi entender esta dimensión es una de las facetas más deseables y extraordinarias de la metodología transdisciplinaria de Basarab Nicolescu y que el pensamiento complejo de Edgar Morin explora también de forma magistral. 
No obstante, Basarab Nicolescu, busca a mi entender implícitamente "salvar" el principio de no contradicción del pensamiento racional moderno, es decir la afirmación casi de "vida o muerte" ontológico-epistemológica de que A y no-A no pueden ser iguales. A mi entender Basarab Nicolescu busca, desde un ethos "racional moderno", salvaguardar la "sanidad" de un mundo estable y homogéneo a la luz de una mente que anhela un orden y regularidad en el conocer y vivir el mundo (Berman 1987). Es paradójico cómo Basarab Nicolescu transgrede el statu quo racionalista, cuando nos dice que esta "ecuanimidad” lógica de no admitir la lógica del tercero incluido (A y no-A no pueden ser ambos iguales a $\mathrm{T}$ ) asumida en un universo de una pieza y homogéneo del positivismo, está fundada sobre una ontología de gran ingenuidad. Complementariamente Basarab Nicolescu afirma que esta lógica del tercero excluido sí es válida si nos limitamos a un movimiento cognoscitivo en un mismo nivel de realidad. Sugiero que es paradójica la actitud de Basarab Nicolescu, ya que está adoptando en cierto sentido una actitud conservadora, ya que defiende implícitamente la "estabilidad" lógica del mundo dentro de un mismo nivel de realidad (enfatizo esto), al apoyar la prohibición de la contradicción (A=no-A). Por ejemplo, lo que a mi entender nos quiere decir Basarab Nicolescu, es que dentro del nivel de realidad mesoscópico, resulta "imposible” que dos objetos que están muy distantes espacialmente, puedan interactuar con mayor intensidad que otro par que estén a una corta distancia; otro ejemplo es que una persona no puede estar presente en dos lugares al mismo tiempo. Entiendo que ya que Basarab Nicolescu ha estado tratando de construir una metodología alterna “respetable” a aquella del positivismo-reduccionismo (Nicolescu 2002), y que esta última es una especie de imperio absoluto en la academia, sea él muy prudente al no introducir aspectos excesivamente "extraños" a las costumbres mentales del pensamiento moderno, y que quizás esta actitud conservadora busca ganar un estatus de credibilidad apropiado para poder "competir" con las normas dominantes. Sin embargo, creo que en Latinoamérica, por nuestra tradición crítica y alternativa al estatus eurocéntrico dominante, podemos mirar más allá buscando de forma más libre, alternativas sin compromisos con aquello que nos resulta absolutamente evidente que hace agua por todos lados. El rescate y revaloración de nuestras "epistemologías del sur" resulta vital en estos tiempos, sobre todo a la luz de nuestro abierto reconocimiento de la total inviabilidad de la propuesta civilizatoria de la modernidad-globalización y del positivismoracionalismo-reduccionismo (de Sousa Santos 2014, Leff 1998, Medina 2006).

Quiero clarificar con todo detalle de forma crítica un aspecto que aquí está implícito tanto en la Metodología Transdisciplinaria, como en el Pensamiento Complejo: que la herramienta más adecuada y poderosa que podemos aplicar para explorar los detalles de un objeto o proceso "de estudio" dentro de un mismo nivel de realidad, es mediante la actividad investigativa de las disciplinas académicas del conocimiento (si bien iluminadas desde una actitud transdisciplinaria y/o compleja). A la luz de lo que ya dije anteriormente, esto implica que dentro de un mismo nivel de realidad y salvando la "sanidad mental" de lo disciplinario y del racionalismo lógico, no se deben aceptar las contradicciones $(A=n o-A)$ en nuestro investigar 
disciplinar. Esta regla universal es el ejemplo de la premisa mayúscula de "sanidad lógica" del sistema de pensamiento moderno, pero que se desgrana en una serie de reglas y costumbres “aceptables” del pensar racional y académico.

Sin embargo, una exploración sutilmente delicada de la riqueza de la experiencia cotidiana desde el auto-conocimiento en conversación sensorial con mi ser y estar en el mundo, como la que han experienciado los campesinos aborígenes latinoamericanos (Rengifo 1999), nos pudiera permitir darnos cuenta de que hay otros mundos y pensares alternos a esta forma "predominante" que se ha planteado desde el racionalismo. Más adelante abordaré la necesidad de continuar explorando honestamente las faraónicas dimensiones de la crisis epistemológica y civilizatoria en la que nos encontramos como humanidad, y que tiene, como ya hemos dicho, a su principal descuido en el abandono del auto-conocimiento y la pertenencia orgánica del pensar y ser (que es una unidad) en el mundo.

Regresando al problema lógico central, me pregunto si aún dentro de un sólo nivel de realidad es viable pretender que la lógica lineal que excluye la contradicción sea (y todas las costumbres epistémicas que de ella se derivan), tal como lo hace la epistemología positivista, la única forma adecuada de comprender el mundo de una forma coherente y viable (Medina 2006, Rengifo 1999). Creo que negarnos a una exploración honesta, sincera e interesada desde el auto-conocimiento de los límites de este tipo de asunciones, es una ceguera epistemológica y ontológica que nos ha estado sumiendo en profundas inviabilidades humanas y planetarias (Bateson y Bateson 1989, Gadotti 2002, Morin y Kern 1999).

Regresemos a la propuesta transdisciplinaria inicial de Basarab Nicolescu. Es así como la visión y el conocimiento transdisciplinario pueden ser vistos como un complemento a la visión disciplinaria, ya que mientras esta última tiene su validez en los límites de un nivel de realidad (acorde a Basarab Nicolescu), la transdisciplinariedad posibilita al conocimiento del ser humano abordar la unidad multi-niveles de realidad del cosmos y la vida (entiendo cosmos como el mundo, como la totalidad en la que existe nuestro planeta, la cultura, el cielo, el ser, etcétera). Esta posibilidad que abre la actitud transdisciplinaria, tiene lugar a la luz de una metodología que no le huye al tercero incluido en los procesos del mundo real, procesos que ocurren en múltiples niveles de realidad conectada y simultáneamente. Consecuentemente, la actitud transdisciplinaria no se plantea suplantar al conocimiento específico-disciplinario, sino que aspira, complementariamente desde el cuidado (Boff 2002) de un mundo esencialmente complejo, atender el sinnúmero de pendientes que ha dejado el conocimiento científico moderno super-especializado, tales como lo ético, el diálogo multi e inter-disciplinario y de saberes, la visión sistémica-holística, la sustentabilidad, la justicia socio-cultural, etcétera. Creo que resulta claro en estos momentos, que como humanidad y como Planeta Tierra, requerimos de forma dramática este tipo de conocimiento humanizado, tal como lo expresa Leonardo Boff en el título de su libro "Ecología: Grito de la tierra, grito de los pobres" (Boff 1996). 
Creo que es un imperativo ético y humano de estos tiempos, reconocer y caminar esta crisis del conocimiento racional y disciplinario, y que nos ofrece la posibilidad de abrirnos al "auto-conocimiento in vivo del pensar" (Nicolescu 2002), a atender al sujeto transdisciplinario como centro del proceso del conocimiento (Shaw 2010, Varela y col. 1999). Desde mi experiencia, esta es la piedra nodal del camino -permanente- de la actitud transdisciplinaria y de un vivir sustentable en general. Sin embargo dada nuestra educación formal y no formal moderna, nuestra reacción ante esta problemática es “teorizar”, seguir dando vueltas desde el racionalismo, desde las ideas (Vargas-Madrazo y Rehaag 2012). Podemos decir que nos resulta un hábito muy íntimo “enamorarnos” de las palabras y los conceptos como forma de responder ante casi cualquier asunto de nuestro vivir y pensar.

De forma alternativa, como vengo planteando en este texto, nos es posible el cultivo de una reflexividad que crece y se mantiene en mi sercuerpo de lo que estoy siendo, permaneciendo atent@7 y, a partir desde ese "lugar", nutriendo el interés honesto y abierto por la experiencia in vivo del mundo (Bunher 2012, Ouspensky 2007, Shaw 2010, Tracol 2009, Tulku 1990). Me atrevo a nombrar esto como una epistemología de la pregunta, como alternativa a la epistemología del concepto.

Basarab Nicolescu nos invita a iniciar este recorrido desde una consciencia crítica (Freire 1969) y de la mano de la Metodología Transdisciplinaria, lo cual implica la indagación pausada y cuidadosa del sujeto transdisciplinario, es decir, de los escenarios personales y colectivos de crisis del conocimiento desde donde nos movemos como seres humanos modernos y pensantes. Al mismo tiempo, Basarab Nicolescu nos sugiere explorar -también- en lo intelectual, en lo humano y en lo cósmico, las rutas alternas y complementarias a la disciplinariedad irreflexiva, rutas de un conocimiento construido en el caminar transdisciplinario que nos acompaña desde el auto-conocimiento, a abordar la necesaria Unidad del Conocimiento. La lógica de Stéphane Lupasco del tercero incluido multi-niveles (Nicolescu 2002) es, como ya dijimos, una cadena de transmisión que empuja al proceso del conocimiento, es decir al sujeto transdisciplinario, a abordar un objeto y su conocer "a través” de su unidad en su existir en distintos niveles de realidad. Todos aquellos aspectos en un nivel de realidad, que evidencian inquietantes contradicciones, como por ejemplo la contradicción entre desarrollo y sustentabilidad, son una invitación a buscar al tercero incluido (T) vinculado a este par [A / no-A], y que existe en otro nivel de realidad. La investigación rigurosa de los detalles acerca de estos puentes vinculantes entre niveles de realidad, así como las relaciones entre los elementos de esta tripleta lógica, son parte esencial de la materia preciosa que nutre el camino de un conocimiento transdisciplinario, camino central para la supervivencia humana ante la insustentabilidad de los modelos mentales actuales.

Sin embargo, a mi entender, es fácil asumir que los andares que anteriormente describimos, deban ocurrir exclusiva o principalmente dentro de las rutas del quehacer y el pensamiento académico, ya sea disciplinario, 
interdisciplinario o transdisciplinario. ¡Nos pagan para eso, es nuestro interés reproductivo académico casi innato! Reitero cariñosamente, para mí y para la o el lector(a), que es muy fácil decir un "sí” interior a esta crisis y continuar enclaustrad@s dentro de los bordes de la élite institucional del conocimiento académico de la universidad. Más arriba había enfatizado que en estos días resulta inaceptable (inviable) éticamente quedarse con la idea y la praxis de un conocimiento disciplinar "sin mayores problemas" dentro de un nivel de realidad, y por lo tanto de un conocimiento transdisciplinar que busca moverse en varios niveles de realidad, pero "dando por sentado" que las disciplinas le brindarán un conocimiento "más o menos” confiable acerca de sus espacios de investigación. Reconocer este peligro, esta crisis en un nivel un poco más profundo, es una veta que deseo seguir durante las siguientes páginas.

\section{Profundizando la pregunta transdisciplinaria hacia el diálogo de saberes y el conocimiento participatorio}

En este punto, quisiera plantear cuatro problemáticas centrales que se derivan del reconocimiento de la dimensión de la crisis en la que estamos metidos como humanidad y como académic@s:

i. Auto-conocimiento y la calidad del ser: Resulta imposible abordar este camino transdisciplinario y de diálogo de saberes sin reconocer que el aparato racional del "yo-que-piensa”, es una estructura mental del ser basada en la identificación con ideas y creencias, que es totalmente incapaz de sentar las bases de un pensar verdaderamente abierto hacia un auto-conocimiento in vivo, que cultiva la calidad del ser. Este conocer in vivo, ocurre desde el constante reconocimiento de lo que estamos siendo, de la totalidad física-emocionalmental-espiritual que como sujetos del conocimiento somos de instante en instante. En un descuido de esta premisa, resulta imposible emprender el rescate de un conocimiento sustentable, viable. Una experiencia vívida e interesada donde la pregunta corporal-somática de la infinita riqueza de lo que estoy siendo, es el fundamento del sujeto transdisciplinario riguroso (Nicolescu 2002), y no los patrones de ideas con los que estoy constantemente nombrando al mundo (Bohm 2001).

ii. Conocimiento individual-profesional. El conocimiento practicado individualmente por profesionales, es un conocimiento producto de la tradición patriarcal-jerárquica que es profundamente insustentable, y es quizás uno de los principales co-responsables de la crisis humana-planetaria en la que vivimos (Berman 1987, de Sousa Santos 2014, Feyerabend 1981). Abrirnos al re-conocimiento del epistemicidio implícito desde donde se re-producen cotidianamente las formas escolarizadas y formales de conocimiento racional, abre las puertas hacia la posibilidad de co-crear ${ }^{8}$ formas participativas y 
comunitarias de re-apropiación del conocimiento basadas en el autoconocimiento y la calidad del ser. Resulta indispensable reconocer el estatus y control que las y los académicos, 1@s profesionales tenemos por encima del "vulgo", sobre los seres y objetos que "estudiamos”, el poder que la palabra docta, el lenguaje abstracto y la "investigación” tiene y ejerce sobre las otras formas de saberes y conocimientos.

iii. Reflexividad auto-crítica hacia una vida en simplicidad. El conocimiento, sea académico, alternativo o tradicional, requiere ser construido desde una revisión profundamente crítica acerca de las dimensiones de la crisis humana y mi lugar en ellas (Freire 1969). Un ser humano alienado de su lugar integral en su mundo e insensible del dolor y la injusticia social que producimos con nuestro vivir capitalista y globalizado, es incapaz de asumir de instante en instante, las preguntas de un hacer participativo y sustentable en un mundo real en y más allá de la academia. Es desde la humildad, como el humus, a ras de tierra, en la simplicidad cerquita de lo elemental, desde donde es posible re-construir un diálogo sensible de saberes y de seres humanos y no humanos (la voz de los ríos, de las montañas, de 1@sniñ@s, de l@s indígenas, del trueno, de 1@s elementales, etcétera). Es desde este lugar de constante auto-conocimiento crítico, desde donde podemos ir co-construyendo el conocimiento comoco-creador@s de conocimiento transdisciplinario,al cuestionarnos el lugar y las formas de cómo nuestro vivir y nuestros hábitos de vida y de conocimiento, determinan las maneras en que participamos en estos procesos. Resulta inviable continuar en el camino de la reflexividad crítica transdisciplinaria hacia el diálogo participativo de saberes desde el hiperconsumismo, desde los lujos y avaricia tanto material como intelectual que ejercemos las y los académicos en nuestra constante "subida en la escalera del consumo de la escolarización” (Illich 1976, 1985).

iv. Conocimiento más allá de lo disciplinario. Un nivel de realidad es un espacio de vida y conocimiento que no necesariamente responde a los requerimientos ontológicos, epistemológicos y metodológicos que desde la racionalidad moderna y académica se postulan como puntos de partida y llegada. Dentro de un nivel de realidad en específico, pero también en la totalidad de nuestra experiencia en los niveles de realidad, existen formas de conocimiento contradictorias y pluriculturales, las cuales evidencian la necesidad de cuestionarnos la viabilidad de querer salvaguardar a toda costa la consistencia lógica o la primacía (implícita o explícita) del conocimiento disciplinar y/o académico así como lo entendemos y vivimos convencionalmente.

Atendiendo estas cuestiones, algunas de las preguntas más insistentes que se han hecho al respecto de las problemáticas éticas y sociales de la escuela, de la educación y el conocimiento académico, han sido reali- 
zadas por pensadores latinoamericanos como Paolo Freire (Freire 1969), Humberto Maturana (Maturana 2000), Francisco Varela (Varela y col. 1999), Enrique Leff (Leff 1998), Leonardo Boff (Bof 1996, 2002), Orlando FalsBorda (Fals-Borda 1991) o Iván Illich (Illich 1973, 1976, 1985). Para mí, aquí vive uno de los pendientes centrales a re-construir dentro de la auto-formación transdisciplinaria, y que implica la posibilidad de reconocer las propias incoherencias intrínsecas a las formas de conocimiento racionalista, académico disciplinario o exclusivamente individual, y que nos invitan poderosa y delicadamente a salir hacia 1@s otr@s seres humanos no académicos (incluido yo mism@) y hacia el mundo en un diálogo de saberes.

Uno de estos caminos, reside en reconocer que esta crisis de las disciplinas y del racionalismo, es en sí una particularidad de la tradición occidental-moderna ${ }^{9}$, el reconocimiento y la creatividad desatadas desde esta reflexión crítica del conocimiento occidental-moderno, puede ser inspiración para revitalizar y fortalecer un caminar abierto y honesto dentro y a través de otras formas de conocimiento y de vivir "periféricas" de los pueblos no occidentales-modernos. Este es un espacio en el que, tal como comenté al inicio de este texto, las y los académicos podemos re-conocernos en nuestra dimensión latinoamericana y aborigen que participa de los procesos en crisis de nuestra modernidad "periférica”. Esto nos invita a un diálogo de saberes en una polifonía co-creativa de conocimientos y saberes distribuidos y co-operativos, esenciales para la super-vivencia de la humanidad (Heron 1995). Esta es una posibilidad para el ser humano-académic@ de re-construir su razón de ser y hacer en un nuevo ethos dialógico y comprometido académico y educativo.

Es por lo anterior que sugiero que no podemos asumir, como implícitamente se puede entender desde un abordaje limitado de la propuesta de Basarab Nicolescu, que esta forma de conocer disciplinar es la única forma visible y viable (abordable rigurosamente) de conocimiento que ha construido la humanidad en estos siglos, ni siquiera dentro de la propia tribu académica (Feyerabend 1981). De una forma a mi parecer poco crítica y reflexiva, se puede asumir que la metodología transdisciplinaria de Basarab Nicolescu plantea que si resolvemos la incoherencia dentro de lo disciplinar, producida por la lógica lineal del tercero excluido, introduciendo la noción de los múltiples niveles de realidad y la lógica del tercero incluido, $\mathrm{y}$ desde aquí complementamos el quehacer disciplinar con un pensar y hacer transdisciplinar, es posible rescatar un conocimiento académico y humano capaz de revitalizar y humanizar la viabilidad de la empresa del conocimiento humano moderno. No creo que esto sea viable, ni siquiera dentro de los límites del edificio del conocimiento académico, menos aún creo que sea deseable y sano plantearnos a la racionalidad académica, sea disciplinaria o transdisciplinaria, como única o principal guía de un mundo en profunda crisis. Este mundo en crisis ha sido primordialmente forjado dentro de los marcos y con la guía del conocimiento racional y académico, por lo que creo que la co-creación de salidas alternas y sustentables a nuestras crisis mayores y menores, requiere de quedarnos, de forma honesta, a replantear la formas tan abigarradas en que como intelectuales participamos y reprodu- 
cimos los vicios del elitismo académico y el epistemicidio cultural.

Podemos argumentar y construir explicaciones diversas en lo abstracto, en el sentido de que es posible o se está abriendo un diálogo de saberes co-operativo hacia las otras formas de sabiduría popular, pero la realidad universitaria, industrial, de servicios, etcétera, nos dice que esto no está ocurriendo así. Si observamos honestamente lo que se hace en este planeta en cada instante, nos podemos dar cuenta de que este diálogo no está ocurriendo realmente, ni siquiera en los espacios alternativos y de la sustentabilidad. Es vital co-construir alternativas viables a este estado de cosas.

Creo que este planteamiento académico-transdisciplinar, que llamo la "visión cerrada a la profundidad de la crisis", suele parecer viable a la luz de la vida hiper-industrial y tecnológica de las sociedades globalizadas (que vivimos y “disfrutamos” 1@s académicos también), pero indudablemente creo que preponderantemente, no es válido para nuestros pueblos definidos como "subdesarrollados" que, como dije al inicio de este ensayo, viven en una "esquizofrenia" de dos mundos inconmensurables habitando en su corazón y en su vivir. Me parece que no basta con "resolver”, aparentemente, los problemas epistemológicos y ontológicos del conocimiento disciplinario, para ser capaces de co-construir un nuevo edificio académico en el diálogo disciplinar o multi, inter y transdisciplinar. Requerimos continuar el camino de la "vigilia epistemológica", para abrirnos más allá desde una reflexión crítica del proceso de imposición colonial en mi interior de las formas patriarcales de la educación escolarizada del conocimiento racional académico (Bowers 2001, Illich 1976). Creo que todas las sociedades, sean europeas, americanas o de cualquier latitud, han vivido estas contradicciones creativas, y que es a partir de esto que podemos caminar por sendas de regeneración y transformación a partir del reconocimiento honesto de todas estas vivencias que son muy dolorosas intelectual y humanamente, pero quizás son necesarias en nuestro camino como humanidad hacia una posible sustentabilidad.

Esto nos lleva a la necesidad de re-encontrarnos en un largo proceso de sanación (como referí al inicio del ensayo), con nuestro saber e indagación campesino, aborigen, femenino-masculino maduro, vernáculo, empírico, mágico y caótico, propio de nuestro corazón latinoamericano, africano, asiático y aún europeo "no desarrollado", es decir desde nuestras epistemologías del sur y/o originarias (de Sousa Santos 2014, Feyerabend 1981, Medina 2006). Lo anterior implica, que resulta fundamental construir una polifonía dialogante de caminos del conocimiento, que trasciendan el asumir que es en el marco de la validez de lo disciplinar dentro de un nivel de realidad, que exclusiva y/o preponderantemente podemos andar el camino de la metodología transdisciplinaria como parte de la co-creación de un conocimiento sustentable y cuidadoso de lo humano. Reitero, a mi entender, que todo esto que estoy cuestionándome, no es "una nueva temática de investigación”, implica en lo esencial un valeroso acto de detenerse, de activar el auto-conocimiento, y a partir de ahí y siempre ahí, generar proce- 


\section{sos de diálogo de saberes y de conocimiento y praxis participatorias autó- nomas (Heron 1995).}

En última instancia, esto parece implicar la paulatina y generosa autodisolución de la actividad académica, así como la conocemos hoy como institución cerrada y auto-suficiente, para recuperar los caminos participatorios de un diálogo social y comunitario del conocimiento y sus conexiones hacia la gestión de la vida (Fals-Borda 1991, Feyerabend 1981, Heron 1995, Illich 1973, Vargas-Madrazo 2015). Tal como el intelecto requiere de soltar un lugar que ha usurpado en el centro del conocimiento y el pensamiento humano, la academia, el conocimiento disciplinar, inter y transdisciplinar, puede darse cuenta y caminar su amorosa retirada del trono epistemológico colonial al centro del sistema social del conocimiento y la educación en el que se encuentran instalados (Vargas-Madrazo y Ruiz 2015).

\section{Conocimiento co-operativo desde y hacia el diálogo de saberes}

A mi entender la crisis del conocimiento y más aun de la humanidad, está enraizada de manera central, en la insistencia en imponer(nos) desde lo interior y desde lo exterior, la premisa de que el conocimiento racionalista y disciplinar, generado sobre la base de la noción del individuo mentalmente “autónomo”, es LA ruta del pensar. Una de las expresiones de cómo se crea desde aquí la crisis del conocimiento, es cómo esta segmentación de la mente colectiva ${ }^{10}$ hacia el individualismo, acarrea lo que David Bohm ha denominado la “fragmentación del conocimiento” (Bohm 2001).

A nivel de la educación superior y de los conocimientos tecno-científicos de la "razón instrumental”, esta situación se expresa en la especialización de 1@s profesionales que se dedican de forma exclusiva a generar y poner en operación de manera jerárquica e impositiva hacia l@s “legos” de dicho conocimiento. Aun dentro de los intentos de desconolizar(nos) del conocimiento académico positivista-mecanicista, como en la metodología transdisciplinaria o la investigación-acción participativa, seguimos preponderantemente, reproduciendo el modelo de los "proyectos de investigación”, nuestro "ir" a "resolver" los problemas de las comunidades (Peat 2011, Sirolli 1999, Vargas-Madrazo y Ruiz 2015); lo que estoy tratando de esbozar es un posible camino de liberación hacia adentro y hacia afuera de la academia, desde un vigilia epistemológica crítica (Bohm 2001, VargasMadrazo y Rehaag 2012) y una “acción suave” (Peat 2011) que surge desde el auto-conocimiento.

Una pregunta esencial en este punto es si la actividad académica transdisciplinaria está exenta de reproducir este estado de cosas, tanto de la praxis individualista, como de replicar un ejercicio centralista y elitista de conocimiento. La subsiguiente pregunta sería ¿cuáles son las reflexiones 
críticas y de qué formas la actividad académica puede romper este tipo de vicios de manera consciente y viable?

Ya Paul Feyerabend (Feyerabend 1981) plantea en su libro "La ciencia en una sociedad libre”, que la dinámica de los "expertos” y del conocimiento académico como rasero de verdad y pertinencia (sea "liberatoria" o neoliberal), hace agua por todos lados y es insostenible a la luz de una observación de los efectos sociales de tales prácticas (Fals-Borda 1991, Peat 2011, Sirolli 1999). Vinculando esto con una de las reflexiones centrales anteriormente presentadas, me pregunto: ¿es realmente válido plantear que dentro de un nivel de realidad el conocimiento académico representa LA forma visible y confiable de saberes? Asociado a esto, recordemos que había planteado que desde un punto de vista inter-subjetivo e inter-cultural, es deseable preguntarse si se debe esperar que en un nivel de realidad la contradicción A=no-A sea un absurdo, y que por lo tanto, el conocimiento debe construirse exclusivamente siguiendo determinados protocolos (metodologías) del pensamiento y de las lógicas propias del conocimiento académico actual.

Creo que este tipo de dificultades, en mucho están asentadas en la construcción individualista y jerárquica del conocimiento. La lógica de las agendas de investigación y la actividad de academizar la vida, interna o externa, tienden a auto-reproducirse vehementemente (Vargas-Madrazo y Ruiz 2015). Desde mi experiencia, en mi camino de auto-conocimiento, me puedo dar cuenta que lo que identifico como mi "yo" que piensa, no es más que un "imprinting” socialmente plasmado e identificado en y de mi (Morin 2007). Al poner en práctica el tipo de auto-observación que implica un conocimiento in vivo como el que nos invita la metodología transdisciplinaria, me puedo dar cuenta de que, como sugiere Michael de Salzman, "somos incapaces de hacer nada” (Shaw 2010), en el sentido de que desde un conocimiento tan superficial como el que tenemos de nosotr@s mism@s, resulta realmente imposible que podamos honestamente reconocer cómo nuestras acciones o pensamientos han surgido de la identificación forjados desde este “imprinting” (Shaw 2011, Vargas-Madrazo y Rehaag 2012). Quizás, una observación pausada de cómo pueden ocurrir las cosas desde la presencia plena/conciencia abierta (Varela y col. 1999), nos permite darnos cuenta de que desde lo que David Bohm llama "suspensión propioceptiva" de mis identificaciones (Peat 2011, Vargas-Madrazo y Rehaag 2012), puede surgir un flujo de significado compartido en una pequeña comunidad de diálogo (Bohm 2001, Vargas-Madrazo 2015).

Tal como lo plantea John Heron (Heron 1995), la reflexión sobre las raíces de la crisis de inviabilidad humana patriarcal-androcéntrica, nos abre de forma central a la posibilidad de la co-construcción de una cultura participatoria y auto-generativa, como la esencia individual y colectiva del ser humano (Vargas-Madrazo y Ruiz 2015). La academia puede re-construir su inserción amorosa en este nuevo-viejo camino. La posibilidad es andar nuestro camino como co-creador@s permanentes (facilitador@s) (Heron 1995, 1999, Vargas-Madrazo 2105) de conocimientos y praxis liberatorias en 
nuestro "hacer el mundo" de forma cotidiana, social y comunitariamente (Vargas-Madrazo y Ruiz 2015). Deseo reiterar aquí que concibo a una praxis profesional, académica y docente reflexiva y transdisciplinaria sustentable como una actividad de facilitación desde la vigilia epistemológica de procesos de diálogo de saberes y de re-construcción de nuestras realidades humanas y socio-ambientales hacia la co-creación de autonomías comunitarias y territoriales (Adamovsky y col 2011, Vargas-Madrazo 2015). Heron llama a esto una visión participatoria del universo y del ser humano (Heron 1995, Skolimowsky 1995). Desde esta reflexión, podemos plantear que el pluralismo epistemológico, es una consecuencia fundamental de la coconstrucción de una sociedad y de comunidades participatorias en el cuidado de la calidad del ser.

Aquí nos estamos encontrando con una serie de situaciones y dificultades, las cuales nos parecen sugerir que la actitud transdisciplinaria puede significar mucho más que quedarnos en "hacerle unos arreglitos” al pensamiento disciplinario y/o académico, sino que podemos iniciar un camino de auto-conocimiento que nos lleva a la necesidad de reflexionar críticamente acerca de cómo participamos en este edificio jerárquico del conocimiento académico. Se abren así las posibilidades co-creativas de transformar la praxis del conocimiento hacia un diálogo de saberes y hacia el pensar participativo (sujeto-objeto de sus propias problemáticas). Nos encontramos así ya en lo que John Heron ha llamado una visión participativa del cosmos y del conocimiento (Heron 1995).

Deseo culminar este ensayo revalorando algunas de las nociones más importantes de este tipo de prácticas liberatorias que ya están caminando en el mundo, y que en América latina, por ejemplo, Paolo Freire y Orlando Fals-Borda, convirtieron en una semilla fértil que ha fructificado en muchas parcelas de nuestras comunidades y aun de académic@s profundamente comprometid@s con el auto-conocimiento y la justicia social.

La dimensión de lo participativo implica al menos dos ámbitos esenciales: el del conocimiento que se produce y que significa vivir articulado orgánicamente en un mundo del que soy parte. Esto se da en la interpenetración de lo conocido con el o la conocedor(a); lo que implica que, tal como plantea Martin Buber (Buber 1977), que el Ser es siempre algo que se produce en la relación con el otro, es decir el conocimiento es siempre un proceso colectivo y l@s conocedor@s sólo pueden serlo en tanto son conocid@s por otr@s conocedor@s (Heron 1995). Así el pensamiento participativo está íntimamente asociado al proceso del conocimiento experiencial (ciclos de aprendizaje experiencial) (Heron 1995), al autoconocimiento en relación siempre con la o el otr@, lo que permite que el aprendizaje se realice desde la totalidad de la persona (Heron 1995). Todo lo anterior nos lleva al reconocimiento de que la realidad es encontrada sólo en la relación.

Finalmente, por todo lo anterior, podemos decir que el conocer sólo existe en el encuentro con la o el otr@, y éstos en su mundo, mundo que es 
co-creado en el encuentro triádico (yo-tu-mundo) participativo, por lo que la Realidad que surge desde un conocimiento participativo, es una realidad subjetiva/objetiva, que es capaz de nutrir lo que John Heron llama una cultura auto-generativa. 


\section{Notas}

${ }^{1} \mathrm{Al}$ utilizar esta metáfora e imagen, quiero enfatizar la unidad creativa donde la vida y la muerte son opuestos complementarios, co-partícipes de un bucle siempre en movimiento donde tan importante es la muerte como la vida, sin una no existe la otra. Al mismo tiempo, al reconocer y recibir esta dinámica de vida de la muerte-vida-muerte, como personas nos abrimos a recibir la energía creativa que desde este bucle se vierte hacia el mundo, y por lo tanto también hacia nosotras y nosotros.

${ }^{2}$ Humberto Maturana y Francisco Varela plantean que el conocer no es un "plus”, un “proceso emergente" y posterior al vivir. Literalmente el vivir, la vida es y ocurre en un constante conocer. Complementariamente conocer es algo que es posible desde el vivir. Es por esto que sugieren esta figura del lenguaje, un bucle unido de conocer-quees-vivir (Maturana 2000, Varela y col. 1997).

${ }^{3}$ Sin entrar en demasiadas honduras socio-antropológicas, deseo resaltar al usar la palabra pos-moderno, esta condición actual del ser humano donde el proyecto de la modernidad está absolutamente presente y nos controla y guía en cada instante de nuestro vivir, pero al mismo tiempo resulta claro que vivimos en constante crisis de esta empresa de la modernidad. No sabemos a dónde ir, las promesas de la abundancia y felicidad tecno-científicas han sido socavadas, pero por más que reneguemos, no hemos logrado salir o construir alternativas reales a esta condición pos-moderna.

${ }^{4}$ Siguiendo a Edgar Morin, hago uso de las partículas auto y eco para denotar las dimensiones hacia "adentro" y hacia "fuera" de los sistemas y en particular en los humanos (Morin 1999). Auto refiere a los aspectos del individuo, de la construcción y de la vida en la persona en términos principalmente de sus estructuras y procesos interiores. El eco refiere a las relaciones, a la co-determinación desde y hace el entorno de la persona.

${ }^{5}$ La metodología transdisciplinaria propuesta por Basarab Nicolescu, propone tres pilares fundamentales en su hacer: i. El ontológico, que propone que la Realidad existe en diversos niveles de realidad discontinuos, ii. El epistemológico, que plantea la lógica del tercero incluido como alternativa a la lógica lineal aristotélica (ver más abajo en el texto principal), y iii. El "metodológico", que nos habla de la dimensión compleja del espacio articulado e hipercomplejo de los niveles de realidad. El escenario cósmicocognoscitivo en el que "vive” esta metodología, implica la existencia de un "objeto transdisciplinario" con sus niveles de realidad, "un sujeto transdisciplinario" con sus niveles de percepción, así mismo entre los niveles de realidad, por una parte, y entre los niveles de percepción, por el otro, existe un "espacio o zona de infinita no resistencia” a la percepción. Finalmente como espacio de interrelación y cultivo de un vivir entre los universos del sujeto y el objeto transdisciplinario, se prolonga y ensancha a través del hacer en la actitud transdisciplinaria, la zona de infinita no resistencia para formar y nutrir el tercero oculto. La existencia de este tercero oculto como superficie misteriosa es la expresión de lo sagrado en el proceso del vivir y el conocer.

${ }^{6}$ Entramado, red o engramado.

${ }^{7}$ Dado que en español se hace uso del género masculino para designar a ambos el masculino y femenino, lo cual encierra formas patriarcales de construir el lenguaje y el pensamiento, prefiero usar a lo largo del texto otras formas para evitar repetir estos 
patrones. Por lo que uso “a/o” y “@” para referirme a ambos géneros de forma explícita.

${ }^{8}$ El prefijo “co-” implica el hacer colectivo, comunitario y participativo en las acciones humanas y del mundo.

${ }^{9}$ Es importante aclarar que estoy haciendo una generalización considerando el papel que occidente moderno y el colonialismo jugaron en la historia contemporánea a partir del siglo XVI, y que se expresó en la imposición del capitalismo hacia la mayoría de los pueblos "periféricos" del mundo. Sin embargo no es apropiado obviar que en casi todos los pueblos del mundo, se han gestado muchos de estos procesos sociales patriarcales. Baste citar los casos de China y Japón imperial, los imperios musulmánárabe, del Imperio Zarista, de Egipto imperial, e inclusive de las sociedades coloniales Mexica e Inca en América.

${ }^{10}$ El propio David Bohm, ha señalado que los pueblos aborígenes a lo largo de los cientos de miles de años de la humanidad han tendido a generar procesos mentales mediante formas que pueden ser identificadas como colectivas y participativas, más que individuales. 
Polis, Revista Latinoamericana, Volumen 14, $N^{\circ}$ 42, 2015

\section{Bibliografía}

Adamovsky, E. Y col. (2011), Pensar las autonomías: altenrativas de emancipación al capital y el estado, Sísisfo, México D.F.

Bateson, G. y Bateson, M.C. (1989), El temor de los ángeles: epistemogía de los sagrado, Gedisa, Barcelona.

Berman, M. (1987), El reencantamiento del mundo, Cuatro Vientos, Santiago de Chile.

Boff, L. (1996), Ecología: grito de la tierra, grito de los pobres, Dabar, México D.F.

Ídem (2002), El cuidado esencial: ética de lo humano, Trotta, Madrid.

Bohm, D. (2001), Sobre el diálogo, Kairós, Barcelona.

Bonfil, G. (1990), México profundo: una civilización negada, Grijalbo : Consejo Nacional para la Cultura y las Artes, México, D.F.

Bowers, C.A. (2001), Educating for Eco-Justice and Community, University of Georgia Press, Atlanta.

Buber, M. (1977), Yo y Tú, Nueva Visión, Buenos Aires.

Buhner, S.H. (2012), Las enseñanzas secretas de las plantas: La inteligencia del corazón en la percepción directa de la naturaleza, New Traditions, Vermont.

de Sousa Santos, B. (2014), Epistemologías del Sur, Akal, Madrid.

Fals-Borda, O. (1991). Acción y conocimiento: cómo romper el monopolio con investigación - acción participativa, CINEP, Santa Fe de Bogotá.

Feyerabend, P. (1981), La Ciencia en una Sociedad Libre, Siglo XXI, México D.F.

Freire, P. (1969), La educación como práctica de la libertad, ICIRA, Santiago de Chile.

Gadotti, M. (2002), Pedagogía de la Tierra, Siglo XXI, México D.F.

Glendinning, Ch. (1994), My name is Chellis \& I'm in recovery from western civilization, Shamabala, Boston.

Griffin, S. (1978), Woman and Nature: The Roaring Inside Her, Sierra Club Books, San Francisco. 
Heron, J. (1995), Co-operative inquiry: research into the human condition, SAGE Publications, London.

Ídem (1999), The complete facilitator's handbook, Kogan Page, London.

Illich, I. (1973), Tools for conviviality, Harper \& Row, New York.

Ídem (1976), La sociedad desescolarizada, Barral Editores, Barcelona.

Ídem (1985), Energía y Equidad. Joaquín Mortiz, México.

Leff, E. (1998), Saber ambiental: sustentabilidad, racionalidad, complejidad, poder, Siglo XXI-PNUMA, México D.F.

Maturana, H. (2000), El sentido de lo humano, Granica, Bueno Aires.

Medina, J. (2006), Suma Qamaña: Por una convivialidad postindustrial, Garza Azul, La Paz.

Morin, E. y Kern, A. B. (1999), Tierra-patria, Kairós, Barcelona.

Morin, E. (1995), Mis demonios, Kairós, Barcelona.

Ídem (1999), El Método III: El conocimiento del conocimiento, Cátedra, Madrid.

Ídem (2001), El Método I: La naturaleza de la naturaleza, Cátedra, Madrid. Ídem (2007), El Método III: Las ideas , Cátedra, Madrid.

Nicolescu, B. (2002), The manifesto of transdisciplinarity. SUNY Press, New York.

Ouspensky, P.D. (2007), En busca de lo milagroso: fragmentos de una enseñanza desconocida, Eneagrama, Madrid.

Peat, D. (2011). Acción suave: alternativas innovadoras para un mundo en crisis, Kairós, Barcelona.

Rengifo, G. (1999), La enseñanza es estar contento. Educación y afirmación cultural andina. PRATEC, Lima.

Shaw, F. (2010), Notes on The Next Attention, Indications Press, New York.

Sirolli, E. (1999), Ripples from the Zambezi : passion, entrepreneurship and the rebirth of local economies, New Society, Gabriola Island.

Skolimowski, H. (1995), The Participatory Mind: A New Theory of Knowledge and of the Universe, Penguin Books, New York. 
Tracol, H. (2009), The real question remains: Gurdjieff a living call, Morning Light Press, Indiana.

Tulku, T. (1990), Visions of Knowledge: Liberation of Modern Mind: Liberation of the Modern Mind. Dharma Publishing, Berkley.

Varela, F., Thompson, E., y Rosh, E. (1999), De cuerpo presente, Gedisa, Barcelona.

Vargas-Madrazo, E. y Rehaag, I. (2012), Fundamentos epistemológicos del re-aprendizaje Transdisciplinario. Revista de Investigación Educativa 15, julio-diciembre. Xalapa: Inst. Inv. Educativos.

Vargas-Madrazo, E. y Ruiz Cervantes, E. (2015), Haciendo y aprendiendo junt@s para transformar: la indagación co-operativa en la pedagogía. Centro EcoDiálogo, Xalapa (en prensa).

Vargas-Madrazo, E. (2015), sitio Web “Diálogos Comunitarios”, consultado 9-3-2015, https://dialogoscomunitarios.wordpress.com

Recibido: 02.06.2014

Aceptado: 18.03.2015 